\title{
SIMPLIFIED METHODS FOR SELECTING MUTAGENIC AND PHAGE INDUCING AGENTS FROM MICROBIAL PRODUCTS
}

\author{
Y. IKEDA and T. IIJIMA \\ Institute of Applied Microbiology, University of \\ Tokyo, Bunkyo-ku, Tokyo \\ Received March 15, 1965
}

Since the suggestion was made by LwofF(1) in 1953 that there might be some relationship among the mutagenic, phage inducing, and carcinogenic activities of a physical or chemical agent, several workers $(e . g ., 2,3)$ have attempted to make such correlations clear. It appears, however, nobody yet has drawn decisive conclusions. As agents indicating the existence of such correlation, several chemicals are known. For example, 4-nitroquinoline-Noxide is mutagenic $(4,5)$, phage inducing $(6)$ and carcinogenic $(7)$ and mitomycin $\mathrm{C}$ mutagenic (8), phage inducing (9) and anti-tumor (10).

At the present days when any effective method for selecting anti-tumor agents has never been established, trials to find anti-tumor or carcinogenic agents among the mutagenic and phage inducing agents are worth while to continue. Such suggestion has been made by LEIN et al. (11) and ENDo et al. (12). If the proposition is correct, the problem that must be solved at first is to establish a simple screening method directly applicable for selection of mutagenic and phage inducing agents from microbial products.

Two methods have been devised which enable us to select mutagenic and phage inducing agents on plates. The first method is based on the mutation of T2 phage from $h^{+}$to $h$, and the second method on the induction of $\lambda$ phage from a lysogenic Escherichia coli. The principles described above are not new, but the advantages of these methods are that they are directly applicable to the cultured broth.

\section{MATERIALS}

Strains. Four strains of E. coli, B, B/2, K12( $\lambda)$, and $\mathrm{K} 12 \mathrm{~S}$, and two bacteriophages, T2 and $\lambda$, were used. The phage titer was assayed by the double layer method using strain B for T2 and strain K12S for $\lambda$ as indicators. T2 phage solution was prepared as follows : phage and growing cells of strain $\mathrm{B}$ were mixed in a ratio of $100: 1$ in nutrient broth, and, after incubation at $37^{\circ}$ for $2 \mathrm{hr}$, a few drops of chloroform were added to induce cell lysis. The phage solution thus prepared contained about $10^{9}$ phages $/ \mathrm{ml}$.

Media. Basal layer medium: $10 \mathrm{~g}$ Polypepton (Daigo Eiyo Co. Ltd.), $5 \mathrm{~g}$ $\mathrm{NaCl}$, and $10 \mathrm{~g}$ agar in $1,000 \mathrm{ml}$ distilled water. Top layer medium : $10 \mathrm{~g}$ 
Polypepton, $5 \mathrm{~g} \mathrm{NaCl}$, and $7 \mathrm{~g}$ agar in $1,000 \mathrm{ml}$ water. Nutrient broth: $10 \mathrm{~g}$ Polypepton, $10 \mathrm{~g}$ meat extract (Difco), $1 \mathrm{~g}$ yeast extract (Difco), and $3 \mathrm{~g}$ $\mathrm{NaCl}$ in $1,000 \mathrm{ml}$ water. $\mathrm{pH}$ was adjusted to 7.2 with $1 \mathrm{~N} \mathrm{NaOH}$ after sterilization.

Antibiotics. The antibiotics used in this work were supplied from the sources recorded in Table 1.

\section{METHODS AND RESULTS}

\section{Method for selecting mutagenic agents}

Strain B sensitive to T2 $h^{+}$and strain $\mathrm{B} / 2$ resistant to the phage were used. On a plate inoculated with equal numbers of $B$ and $B / 2$ cells, wild type phage produced turbid plaques. No plaques developed, however, when the phage was plated with a large number of $\mathrm{B} / 2$ cells and a small number of $\mathrm{B}$ cells. Mutation from $h^{+}$to $h$ was tested by the employment of later stated plate. If the mutation took place, the $h$ mutants would produce clear plaques.

Two $\mathrm{ml}$ of top layer medium inoculated with $10^{5} h^{+}$phages, $10^{5} \mathrm{~B}$ cells, and $10^{7} \mathrm{~B} / 2$ cells was poured over the basal layer medium in a plate. This control plate gave ten to one hundred plaques when incubated at $37^{\circ}$ overnight, indicating that spontaneous mutation occurred at a frequency of $10^{-4}$ to $10^{-3}$. To test various agents, a few crystals of each sample, usually less than $1 \mathrm{mg}$, were placed on the center of a plate to which the basal medium had been layered. To allow for diffusion of the sample, the plate was left at room temperature for $5 \mathrm{hr}$, and then the top layer was poured on.

Table 1. Selection of mutagenic agents among antibiotics.

\begin{tabular}{|c|c|}
\hline $\begin{array}{l}\text { Antibiotics which gave } \\
\text { positive results }\end{array}$ & $\begin{array}{l}\text { Alazopeptin (1), Azaserine (1), Azomycin (1), Mitomycin C (1), } \\
\text { Porfiromycin (3), Roseolic acid (2). }\end{array}$ \\
\hline $\begin{array}{l}\text { Antibiotics which gave } \\
\text { negative results }\end{array}$ & $\begin{array}{l}\text { Actinomycin D (1), Amphomycin (1), Angustmycin C (1), } \\
\text { Anisomycin (1), Blastmycin (1), Candimycin (1), Cellocidin (1), } \\
\text { Cordycepin (1), Cyclohexamide (1), Cycloserine (1), Echino- } \\
\text { mycin (1), Eurocidin (1), Fermicidin (1), Leucomycin (1), } \\
\text { Nebrarine (2), Novobiocin (1), Nystatin (1), Pyridomycin (1), } \\
\text { Pathocidin (2), Sarkomycin (1), Thiazolidone antibiotics (1), } \\
\text { Toyokamycin (2), Tubercidin (2). }\end{array}$ \\
\hline $\begin{array}{l}\text { Antibiotics whose mu- } \\
\text { tagenic activities could } \\
\text { not be determined }\end{array}$ & $\begin{array}{l}\text { Althiomycin (1), Amicetin (1), Fradiomycin (1), Gramicidin J } \\
\text { (1), Griseolutein (1), Hygroscopin (1), Oleandomycin (1), } \\
\text { Thiolutin (1), Viomycin (1). }\end{array}$ \\
\hline
\end{tabular}

(1) From the Division of Antibiotics, Institute of Applied Microbiology, University of Tokyo.

(2) From the Laboratory of Antibiotics, Institute of Physical and Chemical Research, Tokyo.

(3) From the Lederle Laboratories, Pearl River, New York. 
Plates 1 to 4 show the results of testing the mutagenic activities of 2-aminopurine (Nutritional Biochemicals Corp.), azaserine, mitomycin C, and azomycin, respectively. The clear zone observed in the center represents either inhibition of bacterial growth by the sample or confluent lysis induced by mutant phages. When such zone was observed, the sample was placed on a plate to which a mixture of $\mathrm{B}$ and $\mathrm{B} / 2$ cells had been inoculated. The appearance of a clear zone on this plate was interpreted as an indication of inhibition. Much attention was paid to the numerous spots observed around the clear zone. They were plaques produced by $h$ mutants. Thirty eight antibiotics were tested by this method, and those which gave positive results are listed in Table 1.

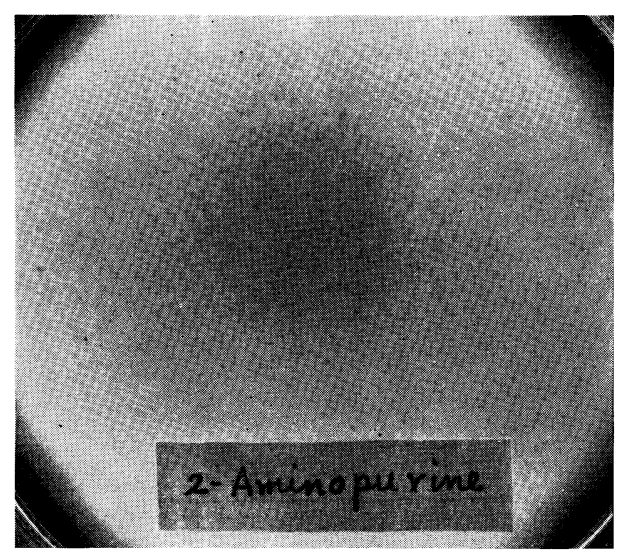

Plate 1. Mutagenic action of 2-aminopurine (powder).

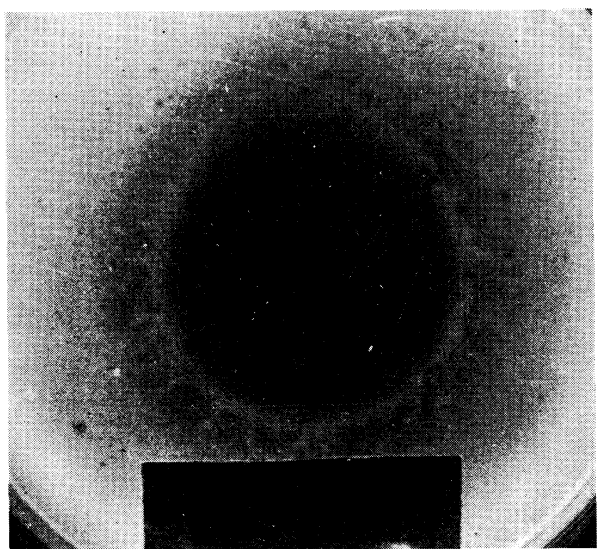

Plate 3. Mutagenic action of mitomycin C (powder).

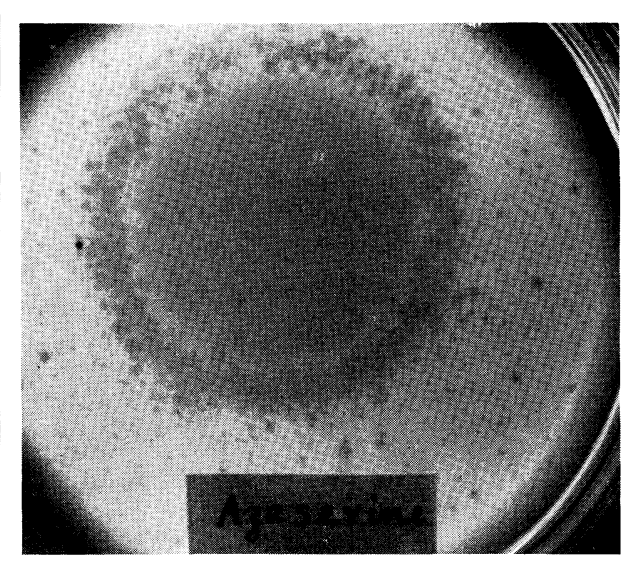

Plate 2. Mutagenic action of azaserine (powder).

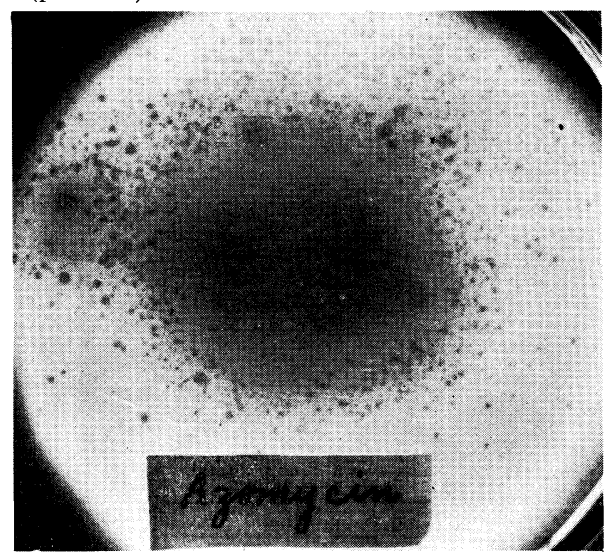

Plate 4. Mutagenic action of azomycin (powder).

Application of this method for selection of strains producing mutagenic agents was attempted. As a model, mitomycin $\mathrm{C}$ was diluted with 
fermented broth of a Streptomyces to a concentration of $3 \mu \mathrm{g} / \mathrm{ml}$. Plate 5 shows a plate on which a metal cylinder filled with the mitomycin solution was placed. As can be seen, the mutagenic activity of mitomycin $\mathrm{C}$ is distinct at this concentration. Although no attempt has been made with the fermented broth of a microorganism, the result described above suggests that the method is directly applicable for selection of strains producing mutagenic agents.

\section{Method for selecting phage inducing agents}

The method described in the following section is based on the principle that $\lambda$ phage induced from a lysogenic strain may form a lytic zone around the sample.

Two ml of top layer medium inoculated with $10^{7}$ cells of $E$. coli $\mathrm{K} 12(\lambda)$ was poured on a plate to which basal medium had been layered. The plate

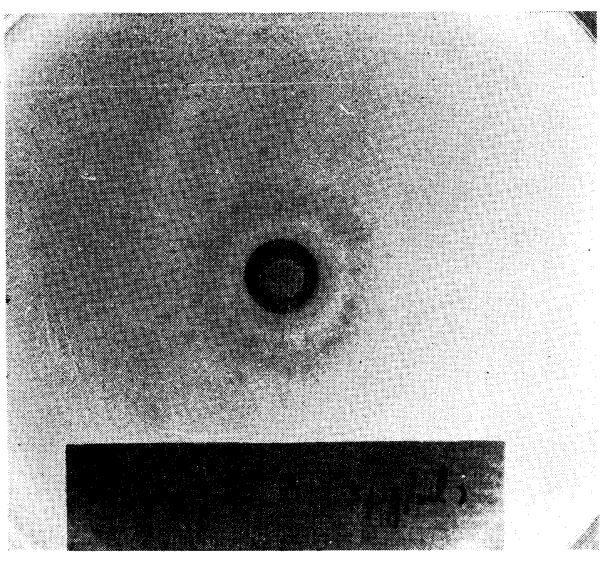

Plate 5. Mutagenic action of $\mathrm{mi}$ tomycin C (cylinder method).

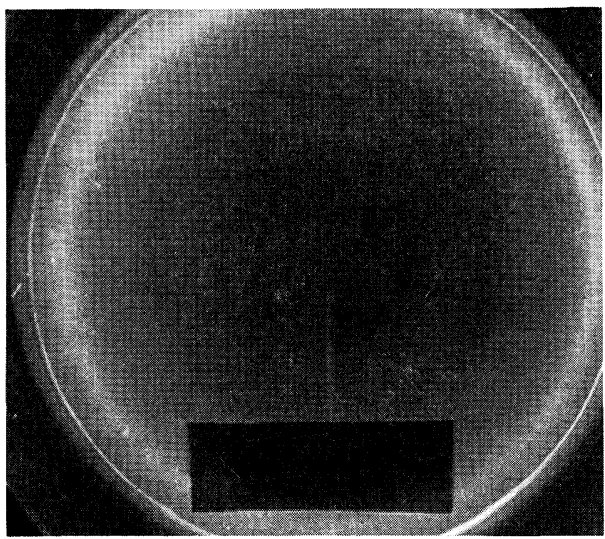

Plate 7. Phage inducing action of porfiromycin (powder).

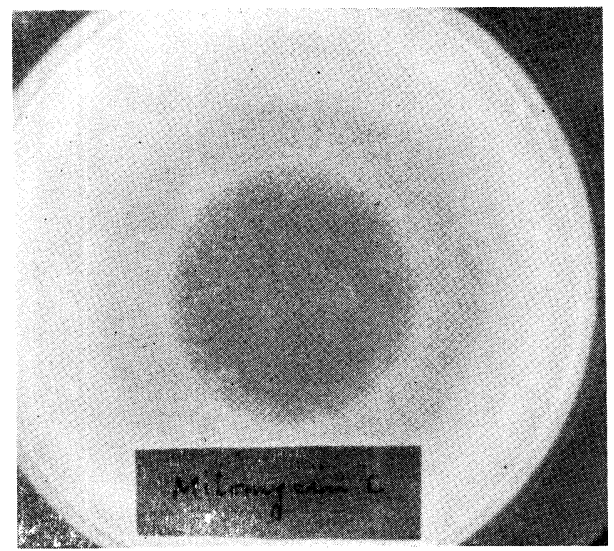

Plate 6. Phage inducing action of mitomycin $\mathrm{C}$ (powder).

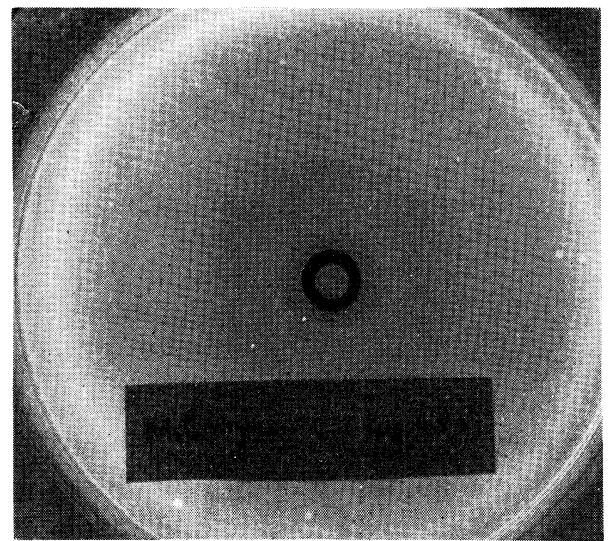

Plate 8. Phage inducing action of mitomycin $\mathrm{C}$ (cylinder method). 
was incubated at $37^{\circ}$ overnight. As this control plate produced no lytic area, liberation of $\lambda$ phage under natural conditions might be small. In the testing series, a few crystals of the sample, usually less than $1 \mathrm{mg}$, were placed on the center of plate for diffusion, and on which the top layer was poured.

Plates 6 and 7 show the results of testing the phage inducing activities of mitomycin $\mathrm{C}$ and porfiromycin. Clear and turbid circles are observed around the samples. The clear circle on the center may represent inhibition of bacterial growth by the test antibiotics and the turbid circle may represent cell lysis by the liberation of $\lambda$ phages. When mitomycin $\mathrm{C}$ was placed on a plate in which non-lysogenic cells of K12S had been inoculated, the turbid circle was not observed.

In addition to the mitomycin $\mathrm{C}$ and porfiromycin, four other antibiotics which had been selected as mutagenic were tested. The results are shown in Table 2.

Table 2. Correlations of mutagenic, phage inducing, and anti-tumor activities of selected agents.

\begin{tabular}{l|c|c|c}
\hline \multicolumn{1}{|c|}{ Antibiotics } & Mutagenic activity & $\begin{array}{c}\text { Phage inducing } \\
\text { activity }\end{array}$ & Anti-tumor activity \\
\cline { 2 - 4 } Alazopeptin & ++ & $+?$ & An analogue of DON \\
$+?(16)$ \\
Azaserine & ++ & $+?$ & $+(17)$ \\
Azomycin & ++ & $+?$ & $?(18)$ \\
Mitomycin C & ++ & ++ & $+(19)$ \\
Porfiromycin & ++ & ++ & $+(20)$ \\
Roseolic acid & + & & $+(21)$ \\
\hline
\end{tabular}

Plate 8 indicates a plate on which a metal cylinder filled with mitomycin C solution $(5 \mu \mathrm{g} / \mathrm{ml})$ is placed in stead of powder. The turbid circle was also produced by this modified method.

\section{DISCUSSION}

Utilization of the agar diffusion method for selection of mutagenic agents is not new. Hemmerly and Demerec (13) and Iyer and Sybalski(14) selected some mutagenic agents active upon $E$. coli by the diffusion method, and Freese (15) devised a simple method for detecting mutation in T4 phage on plates. It must be mentioned, however, that these works were carried out mainly on the basis of reverse mutation from auxotroph to prototroph or from $r$ to $r^{+}$. The system adopted in this work is based on forward mutation. As occurrence of reverse mutation is restricted considerably by the type of the preceding mutation (transition, transversion, or others), it may be said that the forward mutation system is more profitable for selection of mutagenic agents. 
The second advantage is that methods described in this paper are quite simple and directly applicable for selection of strains which produce mutagenic or phage inducing substances. But, there are disadvantages also, and these require further study and discussion. The first concerns the sensitivities of the methods. It is our opinion that the first method, selection of mutagenic agents, is as sensitive as the other methods which have been reported by the present time, but we can not say much about the sensitivity of the second method. Some agents which had been identified as phage inducing, for example, pluramycin, were not phage inducing when tested by this method.

The second problem concerns the case where an agent is mutagenic or phage inducing at concentrations inhibitory to the bacterial growth. In such case, in which the case of pluramycin may be involved, the agents would not be selected. But as most mutagenic or phage inducing agents are used at concentrations lower than inhibitory concentrations, this problem is not so serious. The inhibitory effect and the mutagenic or phage inducing effect of a sample can be distinguished from each other by the employment of two plates as described previously.

As mutagenic and / or phage inducing agents, several antibiotics have been selected. Among them, the mutagenic activities of 2-aminopurine (15), mitomycin $\mathrm{C}(8)$, azaserine (13), and the phage inducing activities of mitomycin $\mathrm{C}(9)$ and porfiromycin (11) had been reported by other workers. New findings are the mutagenic activities of alazopeptin, azomycin, and roseolic acid. The fact that some of the selected agents are also known to be anti-tumor agents is very interesting.

\section{SUMMARY}

Two methods for selection of mutagenic and phage inducing agents on plates have been described. The first method depends on the mutation of T2 phage from $h^{+}$to $h$; the mutation is detected by the appearance of plaques around the diffusion area of the sample. The second method is based on the liberation of $\lambda$ phage from a lysogenic strain of $E$. coli; the induction is detected by the appearance of a turbid circle around the sample. The two methods are quite simple and directly applicable for selection of strains which produce mutagenic or phage inducing substances. Application of these methods as screening methods for selecting anti-tumor agents have also been discussed.

The authors wish to express their sincere thanks to Professors H. Umezawa, H. Yonehara, and N. Tanaka of the Institute of Applied Microbiology, University of Tokyo, and Dr. S. Suzuki of the Institute of Physical and Chemical Research, Tokyo, for the supply of antibiotics used in this investigation. The authors are also indebted to Dr. N. Bohonos of the Lederle Laboratories, Pearl River, N. Y., for the supply of porfiromycin.

This investigation was supported by a Grant in Aid from the Ministry of Education, Japan. 


\section{REFERENCES}

(1) A. LwofF: Bact. Review, 17, 269 (1953).

(2) G. H. SCherR, M. Fishman, and R. H. Weaver: Genetics, 39, 141 (1954).

(3) W. J. BURDETTE: Cancer Research, 15, 201 (1955).

(4) T. OKabayashi: J. Ferm. Technol. (Osaka), 33, 513 (1955).

(5) S. Mashima and Y. Ikeda: Appl. Microbiol., 6, 45 (1958).

(6) H. Endo, M. IshizaWA, and T. KamiYA: Nature, 198, 195 (1963).

(7) W. Nakahara, E. Fukuoka, and T. Sugiura: Gann (Tokyo), 48, 129 (1957).

(8) T. IIJIMA and A. HagIWARA: Nature, 185, 395 (1960).

( 9 ) N. OtSuji, M. SekiguChI, T. IIJima, and Y. TAKagi: Nature, 184, 1079 (1959).

(10) S. Wakaki, H. Harumo, T. Tomioka, G. Shimizu, K. Kato, H. Kamada, S. Kudo, and Y. Fuлімото: Antibiotics \& Chemotherapy, 8, 228 (1958).

(11) J. B. Lein, B. Heineman, and A. Gourevitch: Nature, 196, 783 (1962).

(12) H. Endo, M. Ishizawa, T. Kamiya, and S. Sonoda: Nature, 198, 258 (1963).

(13) J. Hemmerly and M. Demerec: Cancer Research, Suppl. No. 3, 69 (1955).

(14) V. N. IYer and W. SYBalski: Appl. Microbiol., 6, 23 (1958).

(15) E. FreEse: J. Mol. Biol., 1, 87 (1959).

(16) J. Ehrlich, G. L. Coffey, M. W. Fisher, A. B. Hillegas, D. L. Kobberger, H. E. Machamer, W. A. Rightsel, and F. R. Rolgner: Antibiotics \& Chemotherapy, 6, 487 (1956).

(17) C. C. Stock, D. A. Clarke, H. C. Relly, C. P. Rhoads, and S. M. Buckley: Nature 173, 71 (1954).

(18) K. Nitta, T. Takeuchi, T. Yamamoto, and H. Umezawa: J. Antibiotics, Ser. A, 8, 120 (1955).

(19) K. Sugiura: Cancer Research, 19, 438 (1959).

(20) J. S. Evans, E. A. Musser, and J. E. Gray: Antibiotics \& Chemotherapy, 11, 445 (1961).

(21) D. W. Renn, I. Trumees, and R. V. RaO: Antimicrobial agents and Chemotherapy (American Soc. for Microbiology, edited by J. C. Sylvester), pp. 760-1080 (1962). 